Review

\title{
Optimizing diet of children with mental disorders
}

\author{
Elena A. Lugovaya, Inessa V. Averyanova \\ Scientific Research Center "Arktika”, Fareastern Branch of the Russian Academy of Sciences, Magadan, Russia
}

Received 25 May 2020, Revised 20 October 2020, Accepted 5 November 2020

(C) 2020, Lugovaya E.A., Averyanova I.V.

(C) 2020, Russian Open Medical Journal

\begin{abstract}
When monitoring principles of nutrition for children with mental health problems who study in specialized institutions of the Russian Federation or live in boarding schools, it has been revealed that there is no special adapted diet for them. According to the World Health Organization (WHO), unbalanced diets along with lifestyle habits are the main risk factors for chronic diseases, which can develop together with disorders in intellectual and cognitive abilities. Our objective was to study reference data for identifying and summarizing the nutritional characteristics typical for children requiring special medical care. The review has presented data of foreign and national authors, as well as data obtained with the "Arktika" Research Scientific Center of the Far Eastern Branch of the Russian Academy of Sciences, on the elemental status observed in children with autism spectrum disorders, and the nutritional characteristics of the diet kept by residents of Magadan Region under conditions of the Far North. Based on the data, we have made some recommendations for optimizing diet for children with mental disorders.
\end{abstract}

Keywords: children with mental disorders, diet, Far North, recommendations.

Cite as Lugovaya EA, Averyanova IV. Optimizing diet of children with mental disorders. Russian Open Medical Journal 2020; 9: e0408.

Correspondence to Inessa V. Averyanova. Address: Scientific Research Center "Arktika", Fareastern Branch of the Russian Academy of Sciences, 24 Karl Marx St. Magadan, 685000, Russia. Phone: +79246911146. E-mail: Inessa1382@mail.ru.

\section{Introduction}

According to the World Health Organization (WHO), unbalanced diets along with lifestyle habits are the main risk factors for chronic diseases [1], which can develop together with mental disorders.

Both Russian and foreign literature report no dietary patterns approved for a population of children with mental disorders, while it is indicated that there are serious imperfections in traditional methods of nutrition for people of this group $[2,3]$. In general, there are few health promotion activities for adolescents and young people with intellectual disabilities. It should be noted that optimization of nutritional status can help people with mental illness improve their cognitive and emotional performance $[4,5]$.

The problem of special needs that children have in their mental health is relevant. In particular, it is necessary to point out that the number of people with ASD (Autism Spectrum Disorder) in the world has been substantially grown up to $2000 \%$ [6]. According to experts, not only growth and physical development that are influenced by substances entering the human body with food, but psychophysiological, behavioral reactions, and the emotional background are also affected. Features of the nervous system development in ASD children determine their nutritional preferences. A number of authors have noted the elevated consumption of carbohydrates and simple sugars, which directly relate with aggressive or, on the contrary, depressive states in patients [7], while others have reported reduced needs for meat or fish products that are necessary in the diet [8]. The monitoring of the nutrition principles in specialized institutions of our country has found no special diet for children with such diseases. The only feature is an increase in calorie intake, as well as the frequency of meals per day.

Based on the foregoing, the goal of our work was to study scientific literature on the problem of optimizing diet for children with special health needs living in the Far North.

Features of the diet in children with special health care needs

Appendix 1 presents a systematic review of scientific data, both from foreign and Russian sources, regarding characteristics of optimal diet for children with mental disorders.

It should be noted that the growth and development of children are influenced by the North-related regional characteristics of the diet due to extreme environmental factors.

The concept by L.E. Panin (1978) about the formation of the Polar Metabolic Type in the North inhabitants is now largely fundamental with the weakened energetic role of carbohydrates against the background of enhanced lipid and protein metabolism [43], i.e. there is a switch of energy metabolism from its carbohydrate type to the lipid one [44]. These metabolic changes are considered as physiological adaptation to North-related Stress and are caused by direct influence of meteorological and heliogeophysical factors $[43,45]$. The work indicates that a diet with a percentage ratio of proteins, fats and carbohydrates of 16 : 40: 44 is optimum for the Caucasian population of the Far North since it has anti-atherogenic and anti-stress properties. In 
carbohydrate metabolism when carbohydrates prevail in the nutritional structure up to $64 \%$, inadequate rearrangements of the endocrine system are observed accompanied by activation of the pituitary-adrenal system and a decrease in HDL concentration, an increase in triglycerides in the lipid profile [43]. The Northern type of metabolism requires predominance of protein-fat components in food, as well as certain ratios of proteins: fats: carbohydrates, as well as vitamins, macro-, microelements, and other minor components in nutrition [46].

A joint expert consultation of the WHO and the Food and Agriculture Organization of the United Nations on diet and prevention of chronic diseases has concluded that, according to available data, sufficient fiber in the diet is associated with potential health benefits, in particular, with prevention of obesity, diabetes, cardiovascular disease and even various types of cancer [47]. According to the WHO recommendations [48], a modern diet should be characterized by an increased proportion of fruit and vegetables up to $400 \mathrm{~g}$ per day (this is approximately 1 cucumber, 1 tomato, 1 apple, 1 banana, 2 large apricots, 1 orange, half a grapefruit, several strawberries, 1 carrot). Fresh fruits can be replaced with dried fruits. In this case, the norm would change: 80 $\mathrm{g}$ of fresh fruit correspond to $30 \mathrm{~g}$ in dried form, necessary reduction in proportion of trans-fats, as well as a decrease in proportion of mono- and disaccharides - less than $10 \%$ of the daily calorie content (tend to 5\%).

We have analyzed the diet for residents of Magadan Region, which can be characterized by low proportions of proteins, fats, a pronounced deficiency of vitamins and minerals, a violation in fatty acids ratio, insufficient fiber intake against a background of high proportions of di- and monocarbohydrates in the diet. An imbalance in the micro- and macronutrient component of the diet by residents in Magadan city towards a pronounced deficit in most of observed trace elements and vitamins, proteins, fats, carbohydrates with an increased proportion of simple carbohydrates in nutrition is a problem that should be solved together with knowledge about the right nutrition. Based on the above, we note an imbalance that has been common among the entire population of Magadan Region including children with mental disorders [50].

\section{Conclusion}

The results obtained in the reference review have been used to formulate recommendations aimed at correcting the nutrition in order to avoid raising deficiencies in the main macro- and micronutrients and excess in mono-disaccharides in the diet of children with mental disorders, which are certain risk factors for development of chronic diseases in parallel with the mental disorders.

We used the reference review and data on the current diet of Magadan Region residents to make some recommendations aimed at optimizing nutrition of children living in the Far North. The following nutrition components require to be reduced: refined sugars, carbonated drinks, energy-intensive products, red meat, peeled (refined grains), processed meat, fried potatoes, crisps, fullfat dairy products, sauces and dressings, and carbohydrates.

It is important that the following nutrition components are taken in sufficient amounts: Omega- 3 polyunsaturated fatty acids, $\mathrm{Zn}$ and $\mathrm{Mg}, \mathrm{CoQ}_{10}$, vitamins $\mathrm{D}, \mathrm{A}$, and $\mathrm{B}_{6}$, as well as fruit Keeping to a Gluten-Free and Case-Free Diet if possible; In accordance with the concept of the Polar Metabolic Type and WHO recommendations, the following adjustments should be made to the diet: It is necessary to balance nutrition in the following percentage proportion of the main macronutrients: proteins : fats : carbohydrates $=16: 40: 44$. For this it is essential to raise caloric intake due to animal proteins: higher fish and meat (excluding red meat) consumption, and eggs, as well as fiber through fruits, vegetables, legumes, nuts and seeds intake. It is necessary to make proportion of simple carbohydrates lower due to starchy products, bakery, and confectionery products.

\section{Funding}

Budget financing of the "Arktika" Scientific Research Center within the framework of the research theme entitled "Study of the physiological mechanisms of cross-adaptation (hypoxia, cold, hypercapnia) and their trace reactions in humans for the purpose of selecting and predicting their performance in extreme climatic and technogenic environmental conditions".

\section{Conflict of interest}

The authors declare no apparent or potential conflicts of interest related to the publication of this article.

\section{References}

1. WHO. Diet, nutrition and the prevention of chronic diseases. Report of the joint WHO/FAO expert consultation WHO Technical Report Series, No. 916 (TRS 916). Geneva, Switzerland. 2003; 149 p. https://www.who.int/dietphysicalactivity/publications/trs916/en/.

2. van Staveren WA, de Groot LC, Blauw YH, van der Wielen RP. Assessing diets of elderly people: problems and approaches. Am J Clin Nutr 1994; 59(1 Suppl): 221S-223S. https://doi.org/10.1093/ajcn/59.1.221s.

3. Braunschweig $\mathrm{CL}$, Gomez $\mathrm{S}$, Sheean $\mathrm{P}$, Tomey $\mathrm{KM}$, Rimmer J, Heller $\mathrm{T}$. Nutritional status and risk factors for chronic disease in urban-dwelling adults with Down syndrome. Am J Ment Retard 2004; 109(2): 186-193. https://doi.org/10.1352/08958017(2004)109\%3C186:nsarff\%3E2.0.co;2.

4. Humphries K, Traci MA, Seekins T. Nutrition education and support program for community-dwelling adults with intellectual disabilities. Intellect Dev Disabil 2008; 46(5): 335-345. https://doi.org/10.1352/2008.46:335-345.

5. Data Resource Center for Child and Adolescent Health (DRC). http://www.nschdata.org.

6. Kopetz PB, Endowed EDI. Autism worldwide: prevalence, perceptions, acceptance, action. Journal of Social Sciences 2012; 8(2): 196-201. https://doi.org/10.3844/jssp.2012.196.201.

7. Howard AL, Robinson M, Smith GJ, Ambrosini GL, Piek JP, Oddy WH. ADHD is associated with a "Western" dietary pattern in adolescents. $J$ Atten Disord 2011; 15(5): 403-11 https://doi.org/10.1177/1087054710365990.

8. Millichap JG, Yee MM. The diet factor in attention-deficit/hyperactivity disorder. $\quad$ Pediatrics. 2012; 129(2): 330-337. https://doi.org/10.1542/peds.2011-2199.

9. Guesnet P, Alessandri JM. Docosahexaenoic acid (DHA) and the developing central nervous system (CNS) - Implications for dietary recommendations. Biochimie 2011; 93(1): 7-12. https://doi.org/10.1016/i.biochi.2010.05.005.

10. Kris-Etherton PM, Grieger JA, Etherton TD. Dietary reference intakes for DHA and EPA. Prostaglandins Leukot Essent Fatty Acids 2009; 81(23): 99-104. https://doi.org/10.1016/j.plefa.2009.05.011.

11. Stevens L, Zentall SS, Deck JL, Abate ML, Watkins BA, Lipp SR, Burgess $J R$. Essential fatty acid metabolism in boys with attention-deficit hyperactivity disorder. Am J Clin Nutr 1995; 62(4): 761-768. https://doi.org/10.1093/ajcn/62.4.761. 
12. Vancassel S, Blondeau C, Lallemand S, Cador M, Linard A, Lavialle M, et al. Hyperactivity in the rat is associated with spontaneous low level of $\mathrm{n}-3$ polyunsaturated fatty acids in the frontal cortex. Behav Brain Res 2007; 180(2): 119-126. https://doi.org/10.1016/j.bbr.2007.02.032.

13. Lauria HA, Waldrop J. Health Promotion for Individuals With Intellectual Disabilities in the Community. The Journal for Nurse Practitioners 2020; 19(3): 41-44. https://doi.org/10.1016/j.nurpra.2019.09.004.

14. McCann D, Barrett A, Cooper A, Crumpler D, Dalen L, Grimshaw K, et al. Food additives and hyperactive behaviour in 3-year-old and 8/9year-old children in the community: a randomised, double-blinded, placebo-controlled trial. Lancet 2007; 370(9598): 1560-1567. https://doi.org/10.1016/s0140-6736(07)61306-3.

15. Bodnar LM, Wisner KL. Nutrition and depression: implications for improving mental health among childbearing-aged women. Biol Psychiatry 2005; 679-685. https://doi.org/10.1016/j.biopsych.2005.05.009.

16. Lien L, Lien N, Heyerdahl S, Thoresen M, Bjertness E. Consumption of soft drinks and hyperactivity, mental distress, and conduct problems among adolescents in Oslo, Norway. Am J Public Health 2006; 96(10): 1815-1820. https://doi.org/10.2105/ajph.2004.059477.

17. El-Baz FM, Youssef AM, Khairy E, Ramadan D, Youssef WY. Association between circulating zinc/ferritin levels and parent Conner's scores in children with attention deficit hyperactivity disorder. Eur Psychiatry 2019; 62: 68-73. https://doi.org/10.1016/i.eurpsy.2019.09.002.

18. Kozielec T, Starobrat-Hermelin B. Assessment of magnesium levels in children with attention deficit hyperactivity disorder (ADHD). Magnes Res 1997; 10(2): 143-148. https://doi.org/10.1007/springerreference_81564.

19. Mahmoud MM, El-Mazary AA, Maher RM, Saber MM. Zinc, ferritin, magnesium and copper in a group of Egyptian children with attention deficit hyperactivity disorder. Ital J Pediatr 2011; 37: 60. https://doi.org/10.1186/1824-7288-37-60.

20. Bloch $\mathrm{MH}$, Mulqueen J. Nutritional supplements for the treatment of ADHD. Child Adolesc Psychiatr Clin N Am 2014; 23(4): 883-897. https://doi.org/10.1016/i.chc.2014.05.002.

21. Agadzhanjan NA, Notova SV. Elemental status of hair at the stages of development of the body's stress response. Vestnik of the Orenburg State University 2005. (11): 59-61. Russian. http://vestnik.osu.ru/2005 11_1/15.pdf.

22. Gorbachev AL, Lugovaya EA. Features of the elemental status of children with autism spectrum disorder. Trace elements in medicine 2019; 20(3): 20-30. Russian. https://doi.org/10.19112/2413-61742019-20-3-20-30

23. Sidrak S, Yoong T, Woolfenden S. Iron deficiency in children with global developmental delay and autism spectrum disorder. J Paediatr Child Health 2014; 50(5): 356-361. https://doi.org/10.1111/jpc.12483.

24. Bener A, Khattab AO, Bhugra D, Hoffmann GF. Iron and vitamin D levels among autism spectrum disorders children. Ann Afr Med. 2017; 16(4): 186-191. https://doi.org/10.4103/aam.aam 1717.

25. Kostina OV. The role of iron in the pathogenesis of autism spectrum disorders in children. Current Pediatrics 2018; 17(4): 281-286. Russian. https://doi.org/10.15690/vsp.v17i4.1920.

26. Pivina L, Semenova $\mathrm{Y}$, Doşa MD, Dauletyarova M, Bjørklund G. Iron Deficiency, Cognitive Functions, and Neurobehavioral Disorders in Children. J Mol Neurosci 2019; 68(1): 1-10. https://doi.org/10.1007/s12031-019-01276-1.

27. McGrath J, Saari K, Hakko H, Jokelainen J, Jones $P$, Järvelin $M R$, et al. Vitamin D supplementation during the first year of life and risk of schizophrenia: a Finnish birth cohort study. Schizophr Res 2004; 67(23): 237-245 https://doi.org/10.1016/j.schres.2003.08.005.

28. McGrath JJ, Eyles DW, Pedersen CB, Anderson C, Ko P, Burne TH, et al. Neonatal vitamin $D$ status and risk of schizophrenia: a populationbased case-control study. Arch Gen Psychiatry 2010; 67(9): 889-894. https://doi.org/10.1001/archgenpsychiatry.2010.110.
29. Berk M, Sanders KM, Pasco JA, Jacka FN, Williams LJ, Hayles AL, et al. Vitamin $D$ deficiency may play a role in depression. Med Hypotheses 2007; 69(6): 1316-1319. https://doi.org/10.1016/j.mehy.2007.04.001.

30. Howland RH. Vitamin D and depression. J Psychosoc Nurs Ment Health Serv 2011; 49(2): 15-18. https://doi.org/10.3928/02793695-20110111 02

31. Lerner PP, Sharony L, Miodownik C. Association between mental disorders, cognitive disturbances and vitamin D serum level: Current state. Clin Nutr ESPEN. 2018; 23: 89-102. https://doi.org/10.1016/j.clnesp.2017.11.011.

32. Grung B, Sandvik AM, Hjelle K, Dahl L, Frøyland L, Nygård I, et al. Linking vitamin $D$ status, executive functioning and self-perceived mental health in adolescents through multivariate analysis: A randomized double-blind placebo control trial. Scand J Psychol 2017; 58(2): 123-130. https://doi.org/10.1111/sjop.12353.

33. Hebert KJ, Miller LL, Joinson CJ. Association of autistic spectrum disorder with season of birth and conception in a UK cohort. Autism Res 2010; 3(4): 185-190. https://doi.org/10.1002/aur.136.

34. Khemakhem AM, Frye RE, El-Ansary A, Al-Ayadhi L, Bacha AB. Novel biomarkers of metabolic dysfunction is autism spectrum disorder: potential for biological diagnostic markers. Metab Brain Dis 2017; 32(6): 1983-1997. https://doi.org/10.1007/s11011-017-0085-2.

35. Zhou W, Li S. Decreased levels of serum retinoic acid in chinese children with autism spectrum disorder. Psychiatry Res 2018; 269: 469473. https://doi.org/10.1016/j.psychres.2018.08.091.

36. Avraham Y, Berry EM, Donskoy M, Ahmad WA, Vorobiev L, Albeck A, et al. Beta-carotene as a novel therapy for the treatment of "Autistic like behavior" in animal models of Autism. Behav Brain Res 2019; 364: 469479. https://doi.org/10.1016/j.bbr.2017.09.041.

37. Li YJ, Li YM, Xiang DX. Supplement intervention associated with nutritional deficiencies in autism spectrum disorders: a systematic review. Eur J Nutr 2018; 57(7): 2571-2582. https://doi.org/10.1007/s00394-017-1528-6.

38. Bavykina IA, Zvyagin AA, Petrova IV, Nastausheva TL. Markers of gluten intolerance in children with autism spectrum disorders and Down'syndrome. Zh Nevrol Psikhiatr Im S S Korsakova 2018; 118(5. Vyp. 2): 64-68. Russian. https://doi.org/10.17116/jnevro20181185264.

39. Zvyagin AA, Bavykina IA, Bavykin DV. Gastroenterological symptoms in children with autism spectrum disorders. Pediatric Nutrition 2018 16(2): 52-55. Russian. https://doi.org/10.20953/1727-5784-2018-2-52$\underline{55}$.

40. Cekici $\mathrm{H}$, Sanlier N. Current nutritional approaches in managing autism spectrum disorder: A review. Nutr Neurosci 2019; 22(3): 145-155. https://doi.org/10.1080/1028415x.2017.1358481.

41. Lange KW, Hauser J, Reissmann A. Gluten-free and casein-free diets in the therapy of autism. Curr Opin Clin Nutr Metab Care 2015; 18(6): 572-575. https://doi.org/10.1097/mco.0000000000000228.

42. Zvyagin AA, Bavykina IA. Gluten-free diet effectiveness in treatment of autism spectrum disorders in children. Pediatria 2017; 96(6): 197-200. Russian. https://doi.org/10.24110/0031-403X-2017-96-6-197-200.

43. Panin LE. Energy aspects of adaptation. Leningrad, USSR, Medicine Publ. 1978; 192 p. Russian.

44. Boyko ER. Physiological and biochemical basis of human life in the North. Ekaterinburg, Russia: UrO RAS. 2005; 190 p. Russian. https://search.rsl.ru/ru/record/01002806123.

45. Kochan TI. Annual monitoring of the impact of Northern conditions on the metabolism and functioning of the human cardiovascular system. Uspehi fiziologicheskih nauk 2007; 38(1): 55-65. Russian. https://www.elibrary.ru/item.asp?id=9479305.

46. Buganov AA, Agbalyan EV, lonova IE. Influence of nutrition factor on health state of Far North population. Russian Journal of Occupational Health and Industrial Ecology 2003; (4): 25-27. Russian. https://www.elibrary.ru/item.asp?id=17650973.

47. Nishida C, Uauy R, Kumanyika S, Shetty P. The joint WHO/FAO expert consultation on diet, nutrition and the prevention of chronic diseases: 
process, product and policy implications. Public Health Nutr 2004; 7(1A): 245-250. https://doi.org/10.1079/phn2003592.

48. WHO global strategy on diet, physical activity and health: a framework to monitor and evaluate implementation. Geneva, Switzerland: WHO Document Production Services. 2008; 40 p. https://www.who.int/dietphysicalactivity/DPASindicators/en/.

49. Averyanova IV. Macronutrient composition and energy value of the food ration of students of the North-East State University. Novosibirsk State Pedagogical University Bulletin 2018; 8(3); 198-210. Russian. https://doi.org/10.15293/2226-3365.1803.14.

Authors:

Elena A. Lugovaya - PhD, Acting Director, Scientific Research Center "Arktika», Far Eastern Branch of the Russian Academy of Sciences, Magadan, Russia. http://orcid.org/0000-0002-6583-4175.

Inessa V. Averyanova - PhD, Head Researcher, Laboratory for Physiology of Extreme States, Scientific Research Center "Arktika", Fareastern Branch of the Russian Academy of Sciences, Magadan, Russia. http://orcid.org/0000-0002-4511-6782. 
Appendix 1. Nutrition profiles for children with mental disorders, according to reference data

Behavioral changes reflected in the form of hyperactivity in children with special needs, were referred to excessive consumption of refined sugar and

1. certain nutritional supplements.

Omega-3 polyunsaturated fatty acids (Omega-3-PUFA) are necessary for the adequate development and functioning of the nervous system and are

2. indispensable throughout life. In childhood, Omega 3-PUFA is a fundamental nutrient for optimal brain development; in adulthood, it is important for maintaining operational cognitive function. The concentration of Omega 3-PUFA in the body depends mainly on its amount in the diet.

3. Declined Omega-3 fatty acid concentrations in the diet were associated with greater hyperactivity in behavior. An increase in the nervous system hyperactivity in children with special needs is associated with the consumption of the following products: fast food,

4. confectionery, red meat, peeled (refined grains), processed meat, fried potatoes, crisps, soft drinks, cakes, cookies, sauces and dressings, full-fat dairy products, refined sugar.

5. The paper indicates necessity to raise the proportion of fruit in the diet and reduce fast food

6. The consumption of highly refined and energy-intensive foods is considered to be associated with symptoms of nervous system hyperactivity.

7. The so called Western (high-carb) dietary pattern may indicate a higher intake of nutritional supplements, flavors, or colorings, which can lead to

7. hyperactivity, as well as to changes in function of neurotransmitters as a result of poor consumption of trace elements.

8. There is a strong correlation between soft drinks intake and problems in mental health, namely hyperactivity, due to refined sugar consumption.

9. The diet should be enriched with zinc supplements as an adjuvant to the main treatment, which significantly reduces symptoms of hyperactivity

9. syndrome in children.

Magnesium supplements should be taken. The authors indicate a relationship between low magnesium in the blood serum and low magnesium in hair samples in ADHD children (Attention Deficit Hyperactivity Disorder), which is caused by possible pathophysiological mechanisms. Firstly, magnesium has a repressive effect on central and peripheral nervous system. Magnesium deficiency that decreases the calming effect is one of the

main mechanisms of the pathophysiology in hyperactivity. Secondly, in clinical studies, children with hypomagnesemia were described as exhibiting elevated nervous and muscle activity, as well as lowered immunity, which leads to irritability and worsens cognitive skills. Magnesium protects cell membranes from excitatory neurotransmitters such as glutamates (flavor enhancers). Thirdly, magnesium is also involved in the binding of serotonin and dopamine receptors. Thus, low magnesium levels can lead to a decrease in dopamine synthesis and an increase in ADHD associated with neurotransmission.

The research was performed in Magadan Region Educational Center No. 1 among 3-15 year-old children being taught according to adapted

11. educational programs for those with general disorders in psychological development. Low aluminum and zinc, and a tendency to lower iron, and high potassium have been noted in the hair samples of autistic children as specific disorders of mineral metabolism. Low manganese is considered a possible factor in disruption of neurochemical processes in autistic children. Excessive potassium is noted with neurosis and increased physical activity There is a well-reasoned opinion that iron deficiency in children with Autism Spectrum Disorders is a concomitant pathology caused by stereotypical food selectivity. Iron deficiency often accompanies attention deficit, hyperactivity disorder, and ASD; and the association between iron deficiency and

12. autism has been documented. However, the data characterizing iron metabolism in autistic children are confusing. This applies to differences in the level of ferritin, transferrin, and hemoglobin, iron deficiency related anemia, and other parameters. We believe that the tendency to lower iron in children with ASD may be an indicator of autism.

The diet should be enriched with vitamin D supplements. The paper emphasizes its role in development and functioning of the brain as well as in 13. pathogenesis of mental disorders. For example, some studies have shown a relationship between a lack and low levels of vitamin $D$ intake in the first

13. year of life and an increased risk of developing mental illness. In addition, several studies have shown a correlation between vitamin D and depression The relationship between the level of vitamin $\mathrm{D}$ in blood serum with depression and cognitive impairment has also been revealed.

In a randomized, double-blind, placebo-controlled study, subjects with special health care needs with low vitamin D levels showed poorer cognitive

14. test results. The addition of vitamin $D$ to the diet improved their test performance.

15. The study indicates that a reduced vitamin D level in serum was associated with alexithymia, which shows high comorbidity with autism. Vitamin D

15. supplements may reduce the risk or severity of autism.

The study found that insufficient concentrations of $\mathrm{COQ}_{10}$ in serum can strengthen the severity of the manifestations of ASD (Autism Spectrum

16. Disorders).

It was found that decreased vitamin $A$ levels in serum can play a pathogenetic role in autism. The amount of vitamin $A$ in blood serum proved to

17. decline in the subjects with autism and its negative levels significantly correlated with the severity of the course of autism. In addition, another study

7. has demonstrated that beta-carotene (can be converted to vitamin A), administered after birth to newborns from families with a tendency to autism, has the potential to prevent / improve autistic behavior.

18. Pyroxidine (Vitamin $B_{6}$ ) was first used in children with a diagnosis of Autism Syndrome, which has proved to improve speech in some children. In studies, a high frequency of gluten intolerance has been found in children with ASD. Genetic and serological markers of gluten intolerance are identified in 33 children with autism aged $2.5-15$ years old. Moreover, $41.9 \%$ of patients have a genetic predisposition to celiac disease, and $13.8 \%$

19. the subjects show sensitivity to gluten. It should be noted that it is necessary to use an individual approach in administration and evaluation of the effectiveness of GFD (Gluten-Free Diet). It has been shown for ASD patients that gluten-free GFD and casein-free CFD diets and intake of probiotics and enzyme preparations can be equally

20. beneficial to reduce the severity of ASD symptoms. Moreover, the use of sugar, pesticides, genetically modified foods, inorganically processed products and indigestible starches can aggravate the symptoms of the pathology.

K.W. Lange, et al. has analyzed the nutrition of ASD children in the UK. It was found that more than $80 \%$ of the examinees use diet therapy and almost 21. a third (29\%) of them keeps to GFD/CFD. Moreover, according to the parents, there is a significant improvement in the main clinical manifestations of
the disease. 387 parents of pediatric patients with ASD reported positive dynamics in the behavior of the children, their socialization, as well as fewer symptoms of digestive disorders with the use of GFD/CFD, in comparison with those who did not follow the diet. 